\title{
Magnetic Resonance Imaging and T2 Relaxometry of Cerebral White Matter and Hippocampus in Children Born Preterm
}

\author{
LAURENCE J. ABERNETHY, GILLIAN KLAFKOWSKI, LYNDA FOULDER-HUGHES, AND \\ RICHARD W.I. COOKE
}

Department of Radiology [L.J.A., G.K.], Royal Liverpool Children's Hospital (Alder Hey), Liverpool L12 2AP, United Kingdom; and Department of Child Health [L.F.-H., R.W.I.C.], University of Liverpool, Institute of Child Health, Royal Liverpool Children's Hospital (Alder Hey), Liverpool L12 2AP, United

Kingdom

\begin{abstract}
The objective of this study was to determine whether intelligence and minor motor impairments in children who are born preterm without major disability are associated with cerebral white matter (CWM) and hippocampal abnormalities on magnetic resonance imaging (MRI). A total of 103 preterm children were studied at age $7 \mathrm{y}$ with detailed magnetic resonance brain scans, including a T2-mapping sequence from which T2 relaxation times of the CWM and hippocampal formations were calculated. All of the children had no major motor disability, attended normal school, and had undergone assessment of IQ and a test for minor motor impairment (MMI). Twenty children had visible lesions on MRI, which were associated with lower IQ and more frequent MMI. Mean (SD) IQ was 90 (14.1). Twenty-five children were shown to have MMI (Movement ABC at below the fifth centile). This group was shown to have significantly longer $\mathrm{T} 2$ relaxation times for CWM (mean difference $2.1 \mathrm{~ms}$ right, 3.1 $\mathrm{ms}$ left) but not the hippocampus than the children without MMI.
\end{abstract}

ABSTRACT

These differences persisted when only children without visible lesions on scans were considered (mean difference $1.5 \mathrm{~ms}$ bilaterally). There was no significant correlation between IQ and T2 relaxation times. Children who are born preterm without subsequent major neurodisability may, in addition to visible lesions on MRI scans, have a diffuse abnormality of CWM, manifest as an increase in $\mathrm{T} 2$ relaxation time. This abnormality shows a close correlation with minor motor impairment but not with full-scale IQ. (Pediatr Res 54: 868-874, 2003)

AbC, movement ABC
CWM, cerebral white matter
MMI, minor motor impairment
MRI, magnetic resonance imaging
PVL, periventricular leukomalacia

The survival of very preterm infants has improved during the past two decades and led to an increased interest in their long-term neurodevelopmental outcome. Reported series of these infants have shown major disability rates of $10 \%$ to $15 \%$, caused mostly by cerebral palsy and hearing and visual disabilities (1). The majority of the remainder attend normal schools, but one third to one half of these experience behavioral and specific learning difficulties often associated with minor motor impairment (MMI) (2). In the absence of other neurodisability, this syndrome is often referred to as developmental coordination disorder (3). Whereas imaging techniques

Received August 2, 2002; accepted May 27, 2003.

Correspondence: Laurence J. Abernethy, Department of Radiology, Royal Liverpool Children's Hospital, Eaton Road, Liverpool L12 2AP, UK; email: laurence.abernethy@richtr.nwest.nhs.uk

This project was funded by Research Grant MC 010696 from the National Lottery Charities Board, U.K.

DOI: 10.1203/01.PDR.0000091285.84577.4E have clearly shown lesions associated with major neurodevelopmental disabilities, this has not been the case with MMI. There seems to be little if any correlation between cranial ultrasound- or magnetic resonance imaging (MRI)-detected lesions and subsequent functioning at school age despite the high prevalence of such lesions in children born preterm when compared with term control subjects $(4,5)$. Preterm infants have been shown to have smaller brains, less cortical complexity than term children, and often delayed myelination. Quantitative MRI in adolescents who were born preterm has shown significant associations between caudate and hippocampal volumes and intelligence (6) and hippocampal volumes and everyday memory (7)

MRI is highly sensitive to the age-specific changes in myelination; qualitative assessment of the extent of myelination on MR images is a routine part of assessment of brain maturation (8). Visual assessment of gray-white differentiation, $1 \mathrm{H}$ MR spectroscopy and diffusion tensor MRI, and reduction in 
cortical folding all have been used to show delayed cerebral maturation in preterm infants at term $(9,10)$. A simpler quantitative technique, $\mathrm{T} 2$ relaxometry, provides an objective measurement of tissue characteristics; the T2 relaxation time is a physical property of the selected volume of tissue, which mainly reflects the free water content of the tissue. T2 relaxometry of the hippocampal formations has been used to assess patients with complex partial seizures and has been shown to be more sensitive than visual assessment of MR images (11). $\mathrm{T} 2$ relaxometry of the cerebral white matter (CWM) has been described in adult patients with myotonic dystrophy (12) and in children affected by phenylketonuria $(13,14)$, the $18 \mathrm{q}$ syndrome (15), and sexual abuse and drug use (16). Prolonged white matter T2 relaxation times in these patients were considered to represent impaired myelination or gliosis, resulting in an increase in free water concentration. T2 relaxation times have been shown to be high after birth, declining rapidly during the first year of life and achieving adult levels at between 2 and 3 y (17). We hypothesized that MMI in children who are born very preterm is related to evidence of a generalized CWM abnormality rather than only a focal cerebral injury and that similar changes in the hippocampus would reflect IQ deficits.

\section{METHODS}

Participants. All infants who were born before 32 completed weeks in 1991-1992 in the eight hospitals within the Liverpool postal districts were ascertained. Those who died before discharge from hospital or whose mothers were not resident within a Liverpool postal district at the time of birth were excluded.

Initial contact was made with the family doctor via the child's hospital pediatrician to ascertain current health status and school placement. The parents of those children who were alive and attending mainstream schools were then approached to seek consent to take part in the study. When informed consent was obtained, the individual children's schools were then contacted to arrange assessment visits. Most children were tested at their schools, although a few were tested at the Institute of Child Health, Royal Liverpool Children's Hospital, at their parents' request. The study protocol was approved by the local Research Ethics Committee.

Test instruments. Fine and gross motor skills were assessed using age band 2 of the Movement Assessment Battery for Children (Movement ABC) (18). The test comprises eight items, divided into four subsections: manual dexterity, ball skills, static balance, and dynamic balance. The scoring system for each item is from 0 to 5 , ranging from no impairment to severe impairment. The scores for each item are added and converted to percentiles. A score between the fifth and 15th percentiles for age is considered "borderline" impairment, and at or below the 5th percentile "definitely impaired." In this study, a score at or below the 5th percentile was taken to indicate definite MMI.

General intelligence was measured using the Wechsler Intelligence Scale for Children UK (19). Total, verbal, and performance scores were calculated.
Imaging techniques. All parents were approached to ask for agreement for their child to undergo cranial MR scanning at age $7 \mathrm{y}$. When this was obtained from both parent and child, scans were performed on a 0.5 Tesla Philips NT-5 scanner under the supervision of a pediatric imaging team. Scans were assessed qualitatively for signs of perinatal brain injury, including periventricular leukomalacia (PVL), porencephaly, ventricular dilation at any site, and thinning of the posterior portion of the corpus callosum. PVL was recognized by a characteristic triad of abnormalities: abnormally high signal within the periventricular white matter on T2-weighted turbo spin echo (TSE) and fluid attenuated inversion recovery images, loss of periventricular white matter, and focal ventricular enlargement adjacent to regions of abnormal signal intensity.

The scans included a T2 mapping sequence, which allowed measurement of $\mathrm{T} 2$ relaxation times from regions of interest in the CWM and hippocampal formations in both cerebral hemispheres. The total scanning time for each patient was just over $20 \mathrm{~min}$, including $4 \mathrm{~min}$ and $25 \mathrm{~s}$ for the T2 mapping sequence. This technique involved the selection of a single coronal slice, within which the body of the hippocampus and the white matter of the centrum semiovale were represented. By an automated process, 16 separate spin-echo images of this slice were obtained at different echo times, producing a T2 map of the selected slice in which the brightness of each individual pixel represented the calculated T2 relaxation time. Little anatomic information is visible on the T2 map, so regions of interest were drawn manually on the equivalent $\mathrm{T} 1$-weighted image, on which there is clear contrast between gray and white matter. For each examination, a total of four regions of interest were drawn: one in the white matter of the right cerebral hemisphere, one in the white matter of the left cerebral hemisphere, one in the right hippocampus, and one in the left hippocampus. These regions of interest were then pasted onto the T2 map, and the mean T2 relaxation time for each region was calculated (Figs. 1 and 2).

This method is an adaptation of the technique that is routinely used for measurement of $\mathrm{T} 2$ relaxation times of the hippocampal formations in the investigation of patients with temporal lobe epilepsy. T2 relaxometry is more sensitive than visual evaluation of $\mathrm{T} 2$-weighted images in detecting subtle hippocampal sclerosis (9).

Measurements were obtained independently by two radiologists (L.J.A. and G.K.) who were not aware of the motor and psychometric test results. Intraobserver and interobserver reliability of $\mathrm{T} 2$ relaxation time measurement were assessed by the Bland-Altman method (20). For intraobserver differences, 95\% confidence limits of agreement were -2.4 to $2.4 \mathrm{~ms}$ for observer 1 , and -1.9 to $1.7 \mathrm{~ms}$ for observer 2 . For interobserver differences, $95 \%$ confidence limits of agreement were -2.4 to $2.8 \mathrm{~ms}$. Statistical analysis of data was carried out using SPSS-10, using parametric or nonparametric tests depending on the distribution of the data.

\section{RESULTS}

Of a potential cohort of 382 preterm children identified, 33 had moved out of the area or could not be traced, 18 had died, 

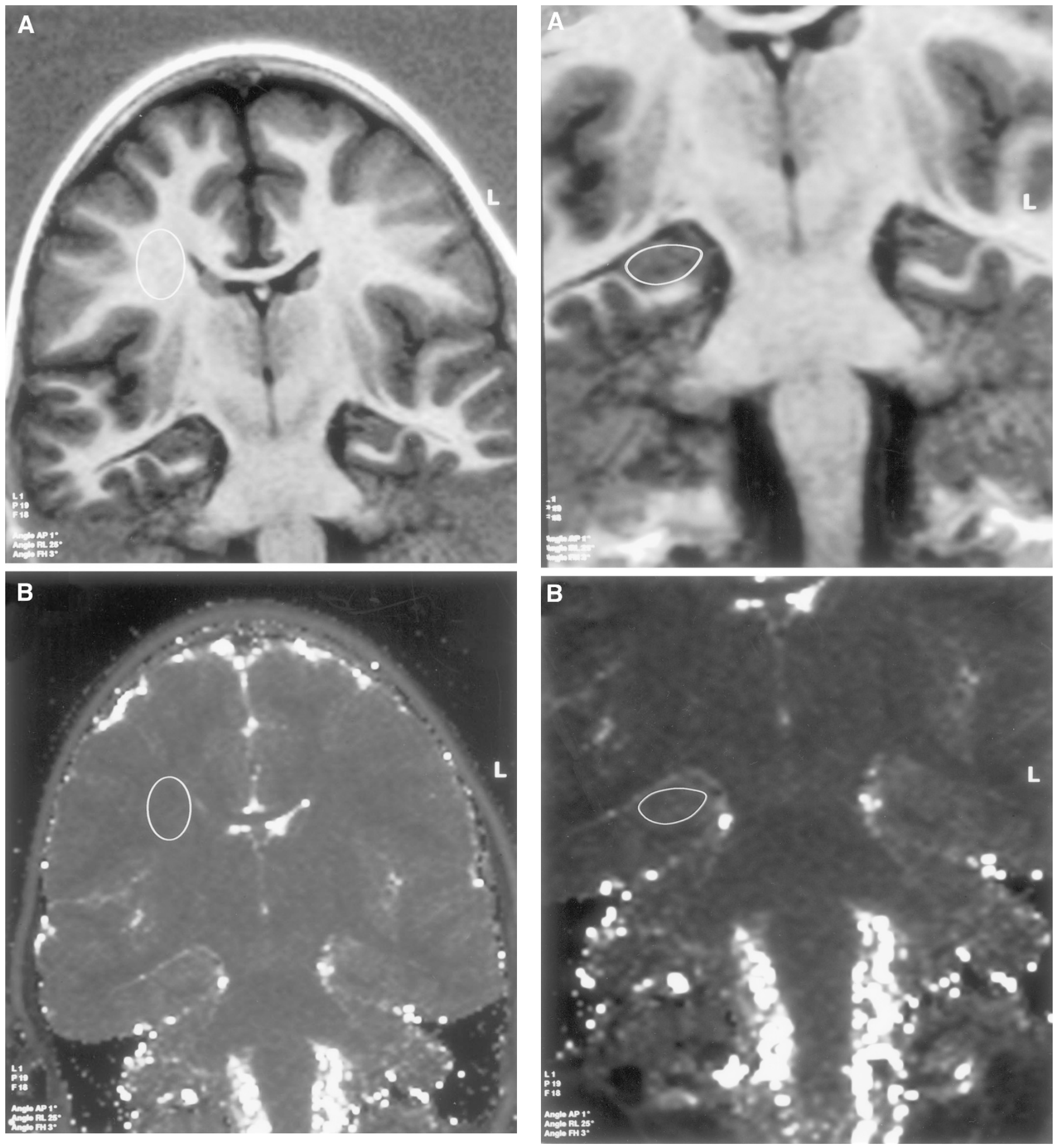

Figure 1. $(A)$ Region of interest drawn within the cerebral white matter on coronal T1-weighted MRI scan. (B) Region of interest pasted onto T2 map.

29 were attending special schools, 16 parents refused permission for their children to be tested, and six failed to attend assessments after giving consent. The 280 children tested comprised $151(53.9 \%)$ boys and $129(46.1 \%)$ girls. Their mean gestational age was 29.8 wk (range 23-32), and their mean birth weight was $1467 \mathrm{~g}$ (range 512-2860); $21.4 \%$ were of $\leq 28$ wk gestation, and $3.6 \%$ were $\leq 24$ wk; $50.4 \%$ were

Figure 2. (A) Region of interest drawn in the body of the hippocampus on coronal T1-weighted MRI scan. (B) Region of interest pasted onto the T2 map.

$<1500$ g birth weight, and $14.6 \%$ were $\leq 1000$ g. There were 215 singleton births, 56 twins, and nine triplets. The mean age at testing was $89.8 \mathrm{mo}$ (range $82-101)$. The total median score on the Movement $\mathrm{ABC}$ was 8.5 (IQR 3.1-15.3). Using the fifth percentile to define a MMI group, $86(30.7 \%)$ fulfilled this criterion. No significant differences in the frequency of MMI 
were seen between the sexes. A significant negative correlation between gestation and birth weight and score on the Movement $\mathrm{ABC}$ was seen (Spearman $\rho,-0.190, p=0.001$ for gestation; $-0.176, p=0.003$ for birth weight). However, a gestational age of $\leq 28 \mathrm{wk}(p=0.24)$ or birth weight $<1500 \mathrm{~g}(p=0.056)$ was not associated with MMI. Mean (SD) total, verbal, and performance IQs were 89.4 (14.2), 92.9 (13.9), and 87.8 (15.6). Total IQ was correlated significantly with gestational age and birth weight (Spearman $\rho 0.264, p<0.001 ; 0.229, p<0.001$ ). The impairment score on the $\mathrm{ABC}$ was significantly correlated with total, verbal, and performance IQ (Spearman $\rho-0.437, p$ $<0.001 ;-0.265, p=0.02 ;-0.442, p<0.001)$.

A total of 103 of the 280 preterm (PT) children tested at school agreed to have an MR scan. Tables 1 and 2 show descriptive perinatal variables and variables at $7 \mathrm{y}$ for preterm children who were scanned and for those who were not scanned. Table 3 shows the median (IQR) test scores for the $\mathrm{ABC}$ and the mean (SD) test scores for the full, performance, and verbal IQs in infants with and without cerebral lesions visible on MRI scans. On qualitative assessment of the MRI scans, 20 children had abnormal scans; 14 had evidence of periventricular leukomalacia (PVL), 14 had ventricular dilation, eight had thinning of the corpus callosum, and two had porencephaly (Table 4). The presence of all lesions except for porencephaly was associated with lower IQs. The ABC scores were significantly impaired only in the presence of marked thinning of the posterior part of the corpus callosum.

Table 5 shows T2 relaxation times for the hippocampal formations and CWM for each side for all children scanned. The $\mathrm{T} 2$ relaxation times are significantly longer in the CWM in infants with impaired scores on the $\mathrm{ABC}(<5 \%)$. When only infants without visible lesions on scan are considered (Table 5 ), the differences persist, although at borderline statistical significance. Similar comparisons of IQ scores to T2 relaxation times (Table 6) showed no statistically significant differences for any region, whether total, performance, or verbal IQ was considered or when test subsets were used.

\section{DISCUSSION}

Learning and behavioral problems have been widely recognized under a variety of names as common sequelae of preterm birth. MMI is often associated with visuospatial problems, poor mathematical ability, and visual problems such as low contrast sensitivity, which in the absence of major cerebral lesions on imaging suggest a cortical developmental problem. Preterm infants have been shown to have smaller brains and impaired white and gray matter development at term compared with full-term control subjects. In the neonatal period, maturational changes on MR mirror infant behavioral scores (21), and reduction in regional cortical volumes in preterm children at 8 years was associated with lower IQ scores (22).

The diagnosis of MMI is problematic in that several different tests are regularly used and the cut-off scores used to define the condition vary. The definition used in this study has been fairly widely used. Other features such as attention deficit, low IQ, and poor social skills are often seen in conjunction with MMI, although the presence of a general medical condition such as cerebral palsy excludes the diagnosis. It has even been suggested that survival after extreme prematurity is such a general medical condition (23). Although the minor impairments seen in such children are diverse, their overall frequency is similar in reported series $(1,4,24-28)$.

This study has confirmed the high prevalence of MMI and lower IQs seen in preterm children without major neurodevelopmental sequelae at primary school age. It has also shown a clear correlation between MMI and IQ and visible lesions on the MRI scans such as PVL, ventricular dilation, and thinning

Table 1. Characteristics of infants in perinatal period who later did or did not have an MRI scan

\begin{tabular}{|c|c|c|c|}
\hline & No MRI scan & MRI scan & $p$ \\
\hline Gestation (wk) & $29.9(2.1)$ & $29.7(2.2)$ & 0.42 \\
\hline Birth weight $(\mathrm{g})$ & $1525(446)$ & $1386(370)$ & 0.009 \\
\hline Head circumference $(\mathrm{cm})$ & $28.5(2.5)$ & $28.4(2.2)$ & 0.69 \\
\hline Maternal hypertension & $19 / 159$ & $18 / 97$ & 0.20 \\
\hline Maternal illness & $18 / 158$ & $6 / 97$ & 0.25 \\
\hline Preterm rupture of membranes & $55 / 159$ & $27 / 97$ & 0.32 \\
\hline Fetal distress & $33 / 159$ & $28 / 97$ & 0.26 \\
\hline Cesarean section & $68 / 159$ & $54 / 97$ & 0.20 \\
\hline Apgar score $1 \mathrm{~min}$ & $6(4-8)$ & $6(4-8)$ & 0.56 \\
\hline Apgar score $5 \mathrm{~min}$ & $9(8-10)$ & $9(7-10)$ & 0.81 \\
\hline Days ventilated & $1(0-4)$ & $1(0-5)$ & 0.56 \\
\hline Days added oxygen & $1(0-8)$ & $2(0-6)$ & 0.91 \\
\hline Hypoglycemia & $25 / 159$ & 9/95 & 0.22 \\
\hline Periventricular hemorrhage left side (ultrasound) & $10 / 159$ & $10 / 95$ & 0.37 \\
\hline Periventricular hemorrhage right side (ultrasound) & $8 / 159$ & $8 / 95$ & 0.49 \\
\hline Parenchymal lesion on either side (ultrasound) & $3 / 159$ & $0 / 95$ & 0.24 \\
\hline
\end{tabular}


Table 2. Characteristics of infants with and without MRI scan at $7 y$

\begin{tabular}{lccc}
\hline & No MRI scan & MRI scan & $p$ \\
\hline Height (cm) & $122(5.7)$ & $121(5.9)$ & 0.25 \\
Weight (kg) & $24.5(4.9)$ & $23.5(4.2)$ & 0.10 \\
OFC (cm) & $51.7(1.9)$ & $51.1(1.8)$ & 0.02 \\
ABC score (IQR) & $8.5(3.5-16.5)$ & $8.25(3.125-15)$ & 0.89 \\
Verbal IQ (SD) & $93(14.7)$ & $93(12.9)$ & 0.75 \\
Performance IQ (SD) & $86(15.2)$ & $91(15.6)$ & 0.01 \\
Total IQ (SD) & $89(14.5)$ & $90(14.1)$ & 0.28 \\
ADHD score (SD) & $54(9.5)$ & $55(10.9)$ & 0.39 \\
\hline
\end{tabular}

OFC, occipiofrontal head circumference; ADHD, standardized score on Conners Hyperactivity Questionnaire completed by class teacher.

Table 3. Lesions seen in 20 preterm infants on MRI scans

\begin{tabular}{|c|c|c|c|c|}
\hline Case & PVL & $\begin{array}{l}\text { Ventricular } \\
\text { dilation }\end{array}$ & $\begin{array}{l}\text { Thinning } \\
\text { corpus } \\
\text { callosum }\end{array}$ & Porencephaly \\
\hline 1 & + & & & \\
\hline 2 & & & + & \\
\hline 3 & & + & & \\
\hline 4 & & + & & \\
\hline 5 & & + & + & \\
\hline 6 & + & & & \\
\hline 7 & + & & & \\
\hline 8 & + & & & \\
\hline 9 & + & + & & \\
\hline 10 & + & + & & \\
\hline 11 & + & + & & \\
\hline 12 & + & + & & \\
\hline 13 & + & + & & \\
\hline 14 & + & + & + & \\
\hline 15 & + & + & + & \\
\hline 16 & + & + & + & \\
\hline 17 & + & + & + & \\
\hline 18 & & + & + & \\
\hline 19 & & & & + \\
\hline 20 & + & + & + & + \\
\hline
\end{tabular}

of the posterior part of the corpus callosum. These changes are likely to represent gross loss, atrophy, or gliosis of the periventricular white matter after the perinatal period. Individually, these visible lesions were not related to IQ deficits, even though the score on the ABC and IQ were significantly correlated. This suggests that the lesions that cause IQ deficits and
MMI are not always the same. IQ relates to brain size and cortical gray matter volume, which may be impaired independent of previous white matter injury such as PVL (29). Although visible white matter damage in the form of PVL, ventriculomegaly, and thinning of the corpus callosum may produce later reduction in cortical gray matter through disruption of cortical association fibers, it is possible that the lesion represented by prolongation of $\mathrm{T} 2$ relaxation time is different and does not affect later brain development. Indeed, it may itself be related to later factors such as poor overall growth. Our results also show that CWM T2 relaxation time is significantly increased in preterm children with MMI. A T2 relaxation time of $>89.5 \mathrm{~ms}$ at this age predicted MMI with a sensitivity of $80 \%$ and a specificity of $60 \%$, compared with any visible MRI lesion with a sensitivity of $32 \%$ and specificity of $84 \%$. This difference persisted when cases with visible MRI lesions were excluded, suggesting that a diffuse abnormality of CWM may be responsible for MMI in most of these children. This could represent a subtle disturbance of white matter myelination, which is independent of the macroscopic changes of PVL.

T2 relaxation time reflects the relative proportion of water to other matter such as myelin, and prolonged times could also result from acute events such as cerebral edema after perinatal hypoxia or ischemia as well as demyelination or delay in myelination. These children were $7 \mathrm{y}$ old, and the immediate effects of perinatal injury were unlikely to have persisted. Gliosis and sclerosis may also present with altered T2 relax-

Table 4. Test scores in presence or absence of cerebral lesions on MRI scans

\begin{tabular}{|c|c|c|c|c|}
\hline & $\mathrm{ABC}$ & FIQ & PIQ & VIQ \\
\hline Any lesion (20) & $10(6.125-25)$ & $83(11.3)$ & $84(13.4)$ & $86(12.7)$ \\
\hline \multirow[t]{2}{*}{ No lesion } & $7(3-13)$ & $93(13.7)$ & $93(15.5)$ & $94(12.6)$ \\
\hline & $p=0.124$ & $p=0.004$ & $p=0.018$ & $p=0.012$ \\
\hline \multirow[t]{2}{*}{ No PVL } & $7(3-13.5)$ & $92(14.5)$ & $92(16.3)$ & $93(13.1)$ \\
\hline & $p=0.147$ & $p=0.017$ & $p=0.063$ & $p=0.215$ \\
\hline Ventriculomegaly (14) & $10(6.3-21.6)$ & $85(8.2)$ & $86(8.0)$ & $88(13.3)$ \\
\hline Thinning corpus callosum (8) & $20(9.25-32)$ & $81(14.3)$ & 77 (12.9) & $88(14.5)$ \\
\hline \multirow[t]{2}{*}{ No thinning corpus callosum } & $7.75(3-13)$ & $92(13.4)$ & $93(15.0)$ & $93(12.8)$ \\
\hline & $p=0.010$ & $p=0.028$ & $p=0.004$ & $p=0.314$ \\
\hline Porencephaly (2) & $20.75(8.5-33)$ & $77(12.7)$ & $77(18.3)$ & $83(5.7)$ \\
\hline \multirow[t]{2}{*}{ No porencephaly } & $8(3-15)$ & $92(13.6)$ & $92(15.3)$ & $93(13.0)$ \\
\hline & $p=0.284$ & $p=0.140$ & $p=0.174$ & $p=0.213$ \\
\hline
\end{tabular}

FIQ, full score on Wechsler-III Intelligence Scale; VIQ, verbal scores on Wechsler-III Intelligence Scale; PIQ, performance scores on Wechsler-III Intelligence Scale. 
Table 5. $T 2$ relaxation times for right and left hippocampus and right and left CWM in infants with MMI (ABC score $<5$ th centile). a) All cases scanned ( $n=103)$; b) Only cases without visible cerebral lesions on MRI scan $(n=83)$.

\begin{tabular}{|c|c|c|c|c|}
\hline & R hippocampus & L hippocampus & R CWM & L CWM \\
\hline \multicolumn{5}{|c|}{ All cases scanned $(n=103)$} \\
\hline $\mathrm{ABC}>5 \%$ & $116.3(4.3)$ & $118.4(10.8)$ & $89.4(2.6)$ & $90.1(2.6)$ \\
\hline $\mathrm{ABC}<5 \%$ & $117.8(4.3)$ & $119.4(4.9)$ & $91.5(3.1)$ & $93.2(6.2)$ \\
\hline \multicolumn{5}{|c|}{ Only cases without visible cerebral lesions on MRI scans $(n=83)$} \\
\hline $\mathrm{ABC}>5 \%$ & $116.0(4.5)$ & $118.9(11.6)$ & $89.6(2.6)$ & $90.2(2.6)$ \\
\hline $\mathrm{ABC}<5 \%$ & $118.3(5.0)$ & $119.9(5.1)$ & $91.1(3.1)$ & $91.7(3.7)$ \\
\hline
\end{tabular}

Table 6. T2 relaxation times for right and left hippocampus and right and left CWM in infants with IQ above and below 85 (-1 SD).

\begin{tabular}{|c|c|c|c|c|}
\hline & R hippocampus & L hippocampus & R CWM & L CWM \\
\hline \multicolumn{5}{|c|}{ All cases scanned $(n=100 *)$} \\
\hline $\mathrm{IQ} \geq 85$ & $116.1(4.1)$ & $118.5(10.7)$ & $89.8(2.5)$ & $91.2(4.2)$ \\
\hline $\mathrm{IQ}<85$ & $118.1(4.5)$ & $118.9(5.6)$ & $90.4(3.7)$ & $90.5(3.6)$ \\
\hline \multicolumn{5}{|c|}{ Only cases without visible cerebral lesions on MRI scan $(n=80)$} \\
\hline IQ $\geq 85$ & $116.0(4.3)$ & $118.9(11.4)$ & $89.7(2.3)$ & $90.6(2.7)$ \\
\hline $\mathrm{IQ}<85$ & $117.8(5.2)$ & $119.2(6.2)$ & $90.6(3.8)$ & $91.0(4.0)$ \\
\hline
\end{tabular}

Three cases not included because of incomplete IQ test data.

ation times, although differences in T2 relaxation times were seen when children with visible evidence of old injury on scans was absent. Further elucidation of the exact nature of these changes may depend on the development of faster methods for MR spectroscopy that could be used practically in pediatric research subjects without sedation.

In the first year of life, the composition of CWM undergoes a rapid sequence of change. Progressive myelination results in an increase in lipid and protein content and a reduction in water content. The water content of the brain decreases from $88 \%$ at birth to $82 \%$ at $6 \mathrm{mo}$. Myelin eventually constitutes $50 \%$ of the weight of white matter in the mature brain (30).

A generalized defect in postnatal myelination could represent a common cause. Such defects are possibly due to injury to axons and oligodendrocyte progenitors by cytokines and free-radicals after perinatal infections or ischemia (31), effects of drugs such as corticosteroids (29), or nutritional deficiencies (32). Identification and modification of these factors may offer the possibility of specific therapies to reduce the burden of disability in children who are born preterm.

Acknowledgments. We thank Dr. Gillian Lancaster, Lecturer in Medical Statistics at the University of Liverpool, for statistical advice and Dr. Alexia Attard for assistance with data collection. Special thanks are due to G. Hughes, D. Garlick, J. Glynn, H. Tyrer, H. Roper, J. Fleming, and L. Dooley for skill and patience in performing the MRI scans and to the parents and children who gave their time to help in this study.

\section{REFERENCES}

1. Marlow N, Roberts BL, Cooke RWI 1993 Outcome at 8 years for children of birth weights of $1250 \mathrm{~g}$ or less. Arch Dis Child 68:286-290

2. Powls A, Botting N, Cooke RWI, Marlow N 1995 Motor impairment in children 12-13 years old with a birth weight of less than 1250g. Arch Dis Child 72:F62-F66

3. American Psychiatric Association 1994 Diagnostic and Statistical Manual of Mental Health Disorders, 4th Ed Rev. Washington, DC, American Psychiatric Association
4. Levene M, Dowling S, Graham M, Fogelman K, Glaton M, Philips M 1992 Impaired motor function (clumsiness) in five year old children: correlation with neonatal ultrasound scans. Arch Dis Child 67:687-690

5. Cooke RWI, Abernethy LJ 1999 Cranial magnetic resonance imaging and school performance in very low birth weight infants in adolescence. Arch Dis Child 82:F116-F121

6. Abernethy LJ, Palaniappan M, Cooke RWI 2002 Quantitative magnetic resonance imaging of the brain in survivors of low birth weight. Arch Dis Child 87:279-283

7. Isaacs EB, Lucas A, Chong WK, Wood SJ, Johnson CL, Marshall C, Vargha-Khadem F, Gadian DG 2000 Hippocampal volume and everyday memory in children of very low birth weight. Pediatr Res 47:713-720

8. Holland BA, Haas DK, Normal D, Brant-Zawadzki M, Newton TH 1985 MRI of normal brain maturation. Am J Neuroradiol 7:201-208

9. Huppi PS, Schuknecht B, Boesch C, Bossi E, Felblinger J, Fusch C, Herschowitz N 1996 Structural and neurobehavioural delay in postnatal brain development of preterm infants. Pediatr Res 39:895-901

10. Huppi PS, Maier SE, Peled S, Zientara GP, Barnes PD, Jolesz FA, Volpe JJ 1998 Microstructural development of human newborn cerebral white matter assessed in vivo by diffusion tensor magnetic resonance imaging. Pediatr Res 44:584-590

11. Jackson GD, Connelly A, Duncan JS, Grunewald RA, Gadian DG 1993 Detection of hippocampal pathology in intractable partial epilepsy: increased sensitivity with quantitative magnetic resonance T2 relaxometry. Neurology 43:1793-1799

12. Di Constanzo A, Di Salle F, Santoro L, Bonavita V, Tedeschi G 2001 T2 relaxometry of brain in myotonic dystrophy. Neuroradiology 43:198-204

13. Ullrich K, Moller H, Weglage J, Schurier G, Bick U, Ludolph A, Hahn-Ullrich H, Funders B, Koch HG 1994 White matter abnormalities in phenylketonuria: results of magnetic resonance measurements. Acta Pediatr Suppl 407:78-82

14. Dezortova M, Hajek M, Tintera J, Hejcmanova L, Sykova E 2001 MR in phenylketonuria-related lesions. Acta Radiol 42:459-466

15. Gay CT, Hardies LJ, Rausch RA, Lancaster JL, Plaetke R, DuPont BR, Cody JD, Cornell JE, Herndon RC, Ghidoni PD, Schiff JM, Kaye CI, Leach RJ, Fox PT 1997 Magnetic resonance imaging demonstrates incomplete myelination in $18 \mathrm{q}$-syndrome: evidence for myelin basic protein haploinsufficiency. Am J Med Genet 74:422-431

16. Anderson CM, Teicher MH, Polcari A, Renshaw PF 2002 Abnormal T2 relaxation time in the cerebellar vermis of adults sexually abused in childhood: potential role of the vermis in stress-enhanced risk of drug abuse. Psychoneuroendocrinology 27:231244

17. Ono J, Kodaka R, Imai K, Itagaki Y, Tanaka J, Inui K, Nagai T, Sakurai K, Harada K, Okada S 1993 Evaluation of myelination by means of the T2 value on magnetic resonance imaging. Brain Dev 15:433-438

18. Henderson SE, Sugden DA 1992 Movement ABC. The Psychological Corporation, London, UK

19. Wechsler D 1992 Wechsler Intelligence Scale for Children, 3rd Ed. The Psycholog ical Corporation, London, UK

20. Bland JM, Altman DG 1986 Statistical methods for assessing agreement between two methods of clinical measurement. Lancet 338:307-310

21. Huppi PS, Schucknecht B, Boesch C, Bossi E, Felblinger J, Fusch C, Herschkowitz N 1996 Structural and neurobehavioural delay in postnatal brain development of preterm infants. Pediatr Res 39:895-901

22. Peterson BS, Vohr B, Staib LH, Cannistraci CJ, Dolberg A, Schneider KC, Katz KH, Westerveld M, Sparrow S, Anderson AW, Duncan CC, Makuch RW, Gore JC, Ment 
LR 2000 Regional brain volume abnormalities and long term cognitive outcome in preterm infants. JAMA 284:1973-1974

23. Holst L, Grunau RV, Whitfield MF 2002 Developmental coordination disorder in extremely low birth weight children at nine years. J Dev Behav Pediatr 23:9-15

24. Elliman AM, Bryan EM, Elliman AD, Walker J, Harvey DR 1991 Coordination in low birth weight seven year olds. Acta Paediatr 80:316-322

25. Goyen TA, Lui K, Woods R 1998 Visual-motor, visual-perceptual and fine motor outcomes in very low birth weight children at five years. Dev Med Child Neuro 40:76-81

26. Hall A, McLeod A, Counsell C, Thompson L, Mutch L 1995 School attainment, cognitive ability and motor function in a total Scottish very low birth weigh population at eight years; a controlled study. Dev Med Child Neurol 37:1037-1050

27. Jongmans MJ, Mercuri E, de Vries L, Dubowitz LM, Henderson SE 1997 Minor neurological signs and perceptual-motor difficulties in prematurely born children. Arch Dis Child 76:F9-F14
28. Luoma L, Herrgard E, Martikainen A 1998 Neuropsychological analysis of the visuo-motor problems in children born preterm at $<32$ weeks of gestation: a 5 year prospective follow up. Dev Med Child Neurol 40:21-30

29. Murphy B, Inder TE, Huppi PS, Warfield S, Zientara GP, Kikinis R, Jolesz FA, Volpe JJ 2001 Impaired cerebral cortical gray matter growth after treatment with dexamethasone for neonatal chronic lung disease. Pediatrics 107:217-221

30. Van der Knapp MS, Valk J 1995 Myelin and white matter. In: Magnetic Resonance of Myelin, Myelination and Myelin Disorders, 2nd Ed. Springer-Verlag, Berlin, pp $1-15$

31. Back SA, Luo NL, Borenstein NS, Levine JM, Volpe JJ, Kinney HC 2001 Late oligodendrocyte progenitors coincide with the developmental window of vulnerability for human perinatal white matter injury. J Neurosci 21:1302-1312

32. Berry MA, Abrahamowicz M, Usher RH 1997 Factors associated with growth of extremely premature infants during initial hospitalisation. Pediatrics 100:640-646 